\title{
Kearifan Lokal Komunitas Anti Speaker (Studi Kasus di Kecamatan Rumpin, Kabupaten Bogor, Jawa Barat)
}

\author{
Moh Jazuli' ${ }^{1}$ Ahmad Yani Nasution ${ }^{2}$ \\ 1,2 Fakultas Ekonomi dan Bisnis, Universitas Pamulang, Indonesia \\ E-mail: dosen01680@unpam.ac.id
}

\begin{abstract}
Article Info
Article History

Received: 2021-05-12

Revised: 2021-07-22

Published: 2021-08-13

Keywords:

Local culture;

Community;

Anti-Speaker.

Abstract

This research is expected to contribute scientifically and academically to the treasures of social science development, especially in the problems that exist in society. Furthermore, it is also hoped that this research can be developed again for researchers who are interested in studying it further. In addition, this study also aims to find out and explore anti-speaker teachings and practices that have developed in Rumpin District, Bogor Regency, West Java as well as to know in more detail the discourse of local wisdom in the archipelago such as anti-speaker teachings which have been a tradition as a wealth of religious treasures in the archipelago. used in this research is a qualitative approach using case study research. The purpose of the case study is to provide a detailed description of the background, characteristics, distinctive character of the case or the status of the individual. Then from the typical characteristics will be made into a general thing. Therefore, this type of research can provide a clear picture of the problems studied, besides that this research is expected to contribute scientifically and academically to the treasures of social science development, especially in problems that exist in society.
\end{abstract}

\begin{tabular}{l}
\hline Artikel Info \\
\hline Sejarah Artikel \\
Diterima: $2021-05-12$ \\
Direvisi: 2021-07-22 \\
Dipublikasi: 2021-08-13
\end{tabular}

Kata kunci:

Kearifan Lokal;

Komunitas;

Anti Speaker.

\begin{abstract}
Abstrak
Penelitian ini diharapkan dapat memberikan sumbangan secara ilmiah dan akademis terhadap khazanah pengembangan ilmu sosial terlebih dalam masalah yang ada di masyarakat. Selanjutnya diharapkan pula penelitian ini dapat dikembangkan kembali bagi peneliti yang tertarik lebih lanjut mengkajinya. Selain itu penelitian ini juga bertujuan untuk mengetahui dan mendalami ajaran dan praktek anti speaker yang berkembang di Kecamatan Rumpin Kabupaten Bogor Jawa Barat sekaligus untuk mengenal lebih detil wacana kearifan lokal di Nusantara seperti ajaran anti speaker yang telah mentradisi sebagai kekayaan kazanah beragama di Nusantara, Pendekatan yang digunakan dalam penelitian ini adalah pendekatan kualitatif dengan menggunakan jenis penelitian studi kasus. Tujuan studi kasus ialah untuk memberikan gambaran secara mendetail tentang latar belakang, sifat-sifat, karakter yang khas dari kasus ataupun status dari individu. Kemudian dari sifat-sifat khas akan dijadikan suatu hal yang bersifat umum. Maka dari itu, tipe penelitian ini dapat memberi gambaran secara jelas mengenai masalah-masalah yang diteliti, selain itu penelitian ini diharapkan memberikan sumbangan secara ilmiah dan akademis terhadap khazanah pengembangan ilmu sosial terlebih dalam masalah yang ada di masyarakat..
\end{abstract}

\section{PENDAHULUAN}

Setiap agama membawa misi sebagai pembawa kedamaian dan keselarasan hidup, bukan saja antara manusia, tetapi juga antar sesama makhluk tuhan penghuni alam semesta ini, dalam terminologi Al Quran sering disebut dengan istilah rahmatan lil 'alamin (rahmat bagi semesta alam), Namun dalam tataran histrorisnya, misi ini tidak selalu artikulatif, selain sebagai alat pemersatu sosial, agama pun dapat menjadi pemicu konflik. Bahkan menurut Schimmel, dua unsur itu menyatu dalam agama. Mungkin pernyataan tersebut agak berlebihan. Tetapi jika melihat perjalanan sejarah dan realitas di muka bumi ini, pernyataan itu menemukan landasan historisnya sampai saat ini, Kearifan lokal merupakan milik manusia yang bersumber dari nilai budayanya sendiri dengan mengungkapkan segenap akal budi, pikiran, hati, dan pengetahuannya untuk bertindak dan bersikap terhadap lingkungan alam dan lingkungan sosialnya (Sibarani, 2012:129).

Kearifan lokal tercermin dalam kebiasaankebiasaan hidup masyarakat yang telah berlangsung lama. Keberlangsungan kearifan lokal akan tercermin dalam nilai-nilai yang berlaku dalam kelompok masyarakat tertentu. Nilai-nilai itu yang menjadi pegangan kelompok 
masyrakat tertentu yang biasanya akan menjadi bagian hidup yang tidak terpisahkan, yang dapat diamati melalui sikap dan prilaku sehari-hari (Takari, Zaidan, dan Dja'far, 2015:303).

Pengertian kearifan lokal Kearifan lokal menurut Wibowo dan Gunawan (2015) dalam Ayatrohaedi (1986), merupakan identitas budaya yang berpengaruh dalam bangsa guna membentuk ataupun juga membentuk kebudayaan sendiri agar dapat disaring dan dikaitkan denganbudaya asing sehingga tercipta perilaku dan kemampuan diri. Karena sejatinya kearifan lokal bersatu dengan masyarakat sekitarnya sehingga selalu dilakukan secara efektif agar tetap terjaga, Rahyono (2009) mengemukakan bahwa kearifan lokal ciri khas yang dimiliki oleh suku tertentu yang didapatkan melalui pembelajaran di suku tersebut lalu di kaitkan dengan lingkungan sehari-harinya. Suhartini (2009) mengartikan bahwa kearifan lokal salah satu warisan terdahulu yang dititipkan oleh orangtua dahulu yang berhubungan dengan tata krama kehidupan saat ini dan tata krama tersebut menyatu dalam nilai karakter religi, etnis, budaya serta adat istiadat yang memberikan pengaruh baik.

Seiring perkembangan era modernisasi dan tantangan jaman yang terus berubah, mendorong umat Islam senantiasa dituntut dinamis. Namun, tidak semua umat Islam mengikuti pola kehidupan modernitas disebabkan sebagian umat Islam masih menjaga tradisi dalam implementasi keagamaannya. Komunitas masyarakat Islam Anti-speaker berada di tengah masyarakat Islam dengan menolak penggunaan barang-barang atau alat-alat modern seperti pengeras suara, televisi dan radio dengan dalih bid'ah, Sulit memang ditengah deras arus perkembangan modernisasi, manusia bersifat stagnan dan tidak bergerak dinamis. Di Pedesaan dan di perkotaan sekarang sangat bergantung pada kecanggihan teknologi. Televisi, handphone, radio, internet, dan barang-barang elektronik yang sulit dipisahkan dari gaya hidup masyarakat modern saat ini.

Hampir di setiap rumah pada umumnya terdapat barang-barang seperti itu. Tetapi, masih banyak manusia yang jauh dari hal-hal yang berbau modernisasi termasuk di perkampungan adat atau di pedalaman yang menetap dihutan yang notabene jauh dari peradaban maju. Tetapi ada pula orang-orang yang sengaja menjauhi modernisasi dengan alasan menjauhi kehidupan duniawi karena ingin lebih dekat dengan alam dan Tuhan, jika kita Memasuki wilayah Rumpin dan lingkungan sekitarnya, kita akan sering mendapati masjid atau musala tanpa Toa (speaker). Bukanlah hal yang asing sesungguhnya, terebih dari sebagian desa yang ada di wilayah ini memang sejak lama memberlakukan aturan tidak tertulis berupa larangan menggunakan speaker. Mereka menyebutnya Aspek, singkatan dari anti Speaker, Aturan anti speaker juga tidak hanya berlaku untuk kegiatan di dalam masjid atau mushalla, aturan itu juga diberlakukan bagi mereka yang memiliki hajat seperti melakukan pesta pernikahan atau pesta lainnya. Bahkan Sejumlah alat elektronik yang di dalam wilayah tersebut seperti speaker rumah, televisi atau radio juga tidak diperkenankan digunakan di wilayah tersebut.

\section{METODE PENELITIAN}

Metode yang dipilih oleh penulis adalah penelitian kualitatif deskriptif di mana data yang dihimpun berupa kata atau pernyataan narasumber, gambar kegiatan, dan bukan berupa angka, Menurut Bog dan dan Taylor, seperti yang ungkapkan oleh Lexy J. Moleong, penelitian kualitatif merupakan langka-langkah penelitian yang membentuk data deskriptif berupa perkataan tertulis dari narasumber dan pengamatan perilaku.

\section{HASIL DAN PEMBAHASAN}

\section{A. Kehidupan Masyarakat Anti speaker}

Di daerah Rumpin dan sekitarnya masih terdapat Komunitas Masyarakat Islam anti speaker yang cukup kental di mana masyarakat sekitar sering menyebutnya dengan Komunitas Islam Anti speaker atau Aspek (Singkatan dari Anti speaker). Komunitas ini bergaul dan berbaur seperti biasa dengan Komunitas Masyarakat Islam lainnya, sepintas jika diperhatikan tidak ada bedanya dengan masyarakat lain, yang membedakan adalah tidak adanya alat speaker atau alat pengeras suara yang ladzim ada di dalam Masjid atau Mushola yang digunakan untuk kegiatan Adzan dan Khotbah (ceramah) dan kegiatan lainnya agar radius suara lebih terdengar luas, Bagi Komunitas Masyarakat Islam anti speaker yang merupakan penduduk minoritas di Rumpin ini, di mana alat speaker ini tidak diperbolehkan. Pemahaman Anti speaker ini ternyata tidak terbatas hanya di Masjid saja, bagi Komunitas Masyarakat Islam Anti speaker berlaku juga di rumah-rumah tempat tinggalnya. Televisi, Handphone, Tape Player 
maupun Radio dan segala sesuatu yang berhubungan dengan audio, seperti musik tidak diperbolehkan karena masih berhubungan dengan speaker.

Pemahaman Anti speaker ini berangkat dari pemikiran bahwa pada jaman dahulu atau pada jaman Rasulullah di mana Masjid pada masa itu tidak menggunakan speaker sebagai alat pengeras suara. Mu'adzin yang ingin melakukan adzan, biasanya naik ke atap atau menara Masjid agar radius suaranya terdengar lebih luas. Jadi, penggunaan speaker di Masjid dianggap sebagai suatu bid'ah (tata cara peribadatan yang tidak dicontohkan oleh Rasulullah), Perkembangan selanjutnya, bagi Komunitas Masyarakat Islam Anti speaker yang fanatik beranggapan bahwa penggunaan speaker atau yang berhubungan dengan speaker diharamkan. Komunitas Masyarakat Islam Anti speaker ini telah lama berkembang dimasyarakat apalagi di pedesaan yang masih menerapkan Islam dengan pola tradisional.

Di Kecamatan Rumpin ini masih terdapat kampung-kampung yang masih terdapat komunitas masyarakat Aspek, Persebaran kaum aspek di wilayah Rumpin dan sekitarnya tersebar di beberapa wilayah atau kampung, di antaranya Kp. Ciaul, Kp. Barengkok, Kp. Maloko, Kp. Cijeungir, Kp. Talaga, Kp. Jatinunggal, Kp. Nungggaherang, Kp. Gunung Cabe, Kp. Pabuaran Desa Cipinang serta di beberapa kampung di pinggiran Kecamatan Cigudeg Kab. Bogor, Komunitas Masyarakat Islam Aspek biasanya membentuk sebuah jaringan pengajian yang rutin diselenggarakan di sebuah Majelis atau Madrasah. Di sana orang-orang yang berpemahaman Anti speaker mengaplikasikan pemahaman dari seorang Ulama atau Ajengan yang tentunya tokoh Anti speaker yang dihormati dan ditaati. Peranan Ulama atau Ajengan dalam komunitas tersebut sangat mempengaruhi pemikiran Jemaahnya, karena sosok Ajenganlah yang dianggap paling bisa menafsirkan atau membuat aturan-aturan lain termasuk didalamnya tentang pemahaman Anti speaker ini.

Komunitas Masyarakat Islam Anti speaker lebih memilih sholat dan ibadah lainnya dengan sesama komunitasnya yang anti Speaker dan tidak berbaur dengan yang lain dalam beberapa hal khususnya Shalat berjamah karena mereka akan memilih yang tanpa speaker, begitupun dengan kegiatan majelis-majelis mereka akan memisahkan diri, juga untuk masalah pendidikan, bagi Komunitas Masyarakat Islam Anti speaker yang fanatik, lebih memilih untuk tidak mengenyam pendidikan formal. Banyak mereka, lebih memilih mengajar anak-anak mereka di rumah masing masing, di antaranya banyak juga banyak yang memilih untuk membawa anak-anaknya ke Pesantren tentunya yang Pesantren yang Aspek juga.

Pemahaman Anti speaker di daerah Rumpin dan sekitarnya ini seolah anti dengan modernisasi atau perkembangan jaman, namun secara umum larangan anti speaker ini sebenarnya lebih kepada larangan penggunaan speaker dan Radio dan sebagainya dalam hal yang berhubungan dengan ibadah saja sedang di luar wilayah tersebut masih terdapat toleransi, Bagi masyarakat yang non Aspek, Mengenai haramnya Speaker, Televisi dan lainya, Majlis Ulama Kabupaten Tingkat 2 Bogor pernah membahasnya secara khusus tentang larangan dan haramnya Speaker, Televisi, radio atau sejenisnya dalam sidangnya di Cibogo tanggal 19 - 21 Dzulqaidah $1403 \mathrm{H}$, atau 28 - 30 Agustus 1983 dan difatwakan tanggal 8 Oktober 1983, untuk menaggapi fenomena sebagian ulama serta pengikutnya yang mengharamkan Radio, Televisi, Pengeras suara, Madrasah, MTQ, dan Nikah yang dilakukan oleh pegawai KUA. Juga untuk menanggapi peredaran kitab Kasyful Ghumum di masayarakat yang ditulis oleh Ahmad Kosasih bin H Nahrawi.

Dalam fatwannya memutuskan beberapa hal; pertama, penggunaan pengeras suara (speaker), Radio, TV hukumnya tidak haram; kedua, belajar agama di Madrasah tidak termasuk bidah dhalalah, akan tetapi termasuk bidah mahmudah/hasanah; ketiga, Musabaqoh Tilawatil Quran (MTQ) hukumnya tidak boleh ria; keempat, memilih pemimpin negara (Presiden melaui Pemilu) hukumnya wajib; kelima, pelaksanaan pernikahan oleh Pegawai Kantor Urusan Agama (KUA) hukumnya sah; keenam, pegawai negeri yang menjadi imam shalat hukumnya sah; ketujuh, mengharapkan kepada para Ulama, Asatidz dan para pemimpin agama/ pondok Pesantren untuk memberikan bimbingan serta penjelasan kepada para jamaah dan masyarakat sekitarnya 
B. Ajaran masyarakat anti speaker di Kecamatan Rumpin Kabupaten Bogor Jawa Barat.

Salah satu contoh pesantren yang saat ini masih memegang kuat pemahaman anti speaker di Kecamatan Rumpin adalah Pesantren Cicendo, Cipinang, yang diasuh oleh H. Edih. Pesantren yang saat ini memiliki kurang lebih 70 santri ini sangat memegang teguh ajaran anti speaker. Dalam pesantren ini tidak terdapat Speaker, Televisi, Radio atau Handphone yang digunakan karena memang tidak diperkenankan menggunakannya, $\mathrm{H}$. Edih, Cipinang Rumpin sendiri memiliki guru Abah Sayuti (ayah dari istri H. Edih) yang merupakan pengasuh Pondok pesantren di Kp. Rahong, Tegallega, Cigudeg Bogor di mana Abah Sayuti Inilah salah satu santri yang pernah berguru kepada Mama Gentur (KH. Ahmad Syatibi), Cianjur, Menurut H. Edi, penggunaan media-media yang dilarang tersebut adalah dalalah karena memang tidak pernah digunakan oleh Nabi. Di Pesantren tersebut santri diajarkan mengenai bagaimana hidup khususnya dalam hal beribadah tanpa menggunakan media-media yang dilarang tersebut seperti speaker, televisi dan sejenisnya.

Salah satu Kitab yang digunakan oleh $\mathrm{H}$. Edih sebagai rujukan dalam pelarangan Speaker adalah Dzurrotul Manahi, kitab matan berbahasa sunda karangan H. Dahyatullah bin H. Rahmatullah bin Ahmad Syatibi. Dalam kitab kecil tersebut dikutip beberapa dasar hadist dan fatwa dari beberapa ulama yang kemudian dijadikan dasar pelarangan beberapa media khususnya Radio dan Televisi, Pada sampul kitab tersebut tertulis dengan bahasa sunda dengan judul kitab Dzurrotul Manahi, dengan keterangan berbahasa sunda:

"Mertelaaken hukumna alat malahi kaya Radio jeng Tipi oge fasade, ditukil sareng diserat ku kaula anu mana pun al Hajj Muhammad Dahyatullah bin al Hajj Rahmatullah bin Almarhum Mama Gentur kaler, pangersa Asyaikh al Hajj Ahmad asy Syatibi ghufarollahulahum wal muslimiina aamiin, yaa robbal aalamiin",

yang jika diterjemahkan ke dalam bahasa Indonesia kurang lebihmenjelaskan hukum alat malahi (mainan) seperti Radio dan Televisi juga keburukannya, dikutip dan ditulis oleh saya $H$. Dahyatullah bin $H$. Rahmatullah bin Alm. Mama Gentur, yang terhormat Syekh H. Ahmad Syatibi ghufarollahulahum wal muslimiina aamiin, Hal senada juga seperti disampaikan oleh $\mathrm{H}$. Tajun Nasroh Qurdhi, Pengasuh Pondok Pesantren Asy Salafiyah Raudhatul Ghina Kp. Sampay, desa Rabak, Kecamatan Rumpin Bogor, yang mengatakan bahwa media yang dilarang seperti Speaker, Radio dan sebagainya adalah jika berkenaan dalam hal ibadah, meskipun pada kondisi yang lebih luas media tersebut juga dibatasi bahkan dilarang dalam penggunaan selain ibadah karena dapat menimbulkan lebih banyak mudharat daripada kemanfaatannya.

Menurut Peneliti el-Bukhari Institute, Alumni Pesantren Hadits Darussunnah dan UIN Syarif Hidayatullah Jakarta, salah satu ulama dari Cirebon yang dalam beberapa tulisannya melarang media Speaker untuk digunakan di Masjid Mushala, majelis-majelis atau sarana ibadah lainnya adalah Syekh Mahmud Mukhtar, sosok ulama yang berijtihad dan menampilkan bentuk kearifan lokal yang menarik, yaitu larangan penggunaan corong atau speaker, Kearifan tersebut tertuang dalam salah satu kitabnya Bida'ul Masajid. Bida'ul Masajid adalah karya Syekh Mahmud Mukhtar, pengasuh Pesantren Darul Ulumisy Syar'iyyah, Bode, Plumbon Cirebon. Beberapa pernyataannya menunjukkan adanya argumen maslahat dalam penolakannya terhadap speaker seperti "menggangu ketenangan umum."

Saat membahas larangan terhadap penggunaan media, paling tidak ada dua bukunya yang menyorot dan mengkritik penggunaan teknologi modern. Yaitu buku Bida'ul Masajid (Bidah-bidah dalam Masjid) dan Qa'idul 'Umyan Ila Hukmi Kaset Al Quran. Dalam dua buku ini, Syekh Mahmud Mukhtar menolak keras penggunaan speaker masjid dan kaset bacaan Alquran, Dalam pendahuluan buku Bidaul Masajid dikatakan, "Amal perbuatan kita orang-orang Islam di dalam melaksanakan ibadah kepada Allah SWT dari hari ke hari semakin memburuk, ngawur, semerawut serta bercampur aduk yang menyimpang jauh dari ajaran Rasulullah saw." (Syaikh Mahmud, Bida'ul Masjid. hlm. 1), selain itu Syekh Mahmud Mukhtar juga menyebutkan tujuh macam bidah yang populer di masyarakat Muslim di mana bidah ketujuh adalah mengeraskan suara di dalam Masjid walaupun hal tersebut adalah dalam rangka 
berdzikir atau membaca Al Quran. Syekh Mahmud Mukhtar mendasarkan pendapatnya pada dua buah hadis yang melarang meninggikan suara dalam masjid yaitu:

"Jannibu masajidakum raf'a ashwatikum"

Artinya: Jauhkan masjid-masjidmu dari suara kerasmu (H.R Ibnu Majah).

Hadist yang lain adalah:

"Lau kuntuma min ahlil balad laauja'tukuma tarfa'ani ashwatakuma fi masjidi rasulillah saw."

Artinya: Kalau kalian asli orang Madinah, niscaya saya hajar kalian dengan pukulan yang menyakitkan, karena kamu mengeraskan suaramu di dalam masjid." (H.R. Al Bukhari).

Terkait larangan yang terdapat dalam hadist tersebut, Syekh Mahmud menulis, "Apalagi mengeraskan suara dengan pakai corong (speaker) yang pasti akan lebih keras seribu kali, apalagi setelah adzan, semakin bertambah dilarang (haram) karena tasywisy yang mengganggu ketenangan umum." ( Syaikh Mahmud, Bida'ul Masjid hlm. 28), Pada bagian lain, Syekh Mahmud Mukhtar mengategorikan penggunaan speaker sebagai bidah dalalah. "Menggunakan pengeras suara/speaker di waktu salat atau khutbah adalah bidah dalalah apabila suara imam atau khatib sendiri sudah bisa sampai/didengar oleh makmum/hadirin." (Bidaul Masaj. hlm. 54), Menanggapi anggapan speaker membantu syiar Islam, Syekh Mahmud menolak anggapan tersebut. "Jangan beralasan pakai speaker itu syiar Islam, Ini juga alasan orang bodoh yang tidak mengerti makna syiar Islam. Syiar itu artinya alamat/tanda. Jadi syiarul Islam artinya alamatul Islam. Apakah patut kiranya speaker dijadikan alamat Islam?" (Syaikh Mahmud, Bida'ul Masjid hlm. 58)

\section{A. SIMPULAN}

Larangan yang terdapat pada komunitas anti speaker ini seperti penggunaan Speaker, Radio, Televisi, Handphone (HP) dan media sejenis adalah dalam hal ibadah, meskipun tidak menutup kemungkinan para ajengan juga melarangnya dalam kegiatan sehari hari untuk menghindari mudharat dari media-media tersebut sehingga dalam hidup bisa lebih digunakan untuk mendekat serta beribadah kepada Allah, Walaupun berbeda pemahaman dan sempat terjadi konflik antara masyarakat Aspek dan non Aspek, namun hubungan masyarakat dengan Komunitas Masyarakat Islam Anti-speaker, secara umum berdampingan dengan baik meskipun gesekan di beberapa keadaan, tempat dan antar tokoh kadang muncul.

Jika ditelusuri, ajaran anti speaker dan sejenisnya yang memuat larangan penggunaan Speaker, Televisi dan lainnya di daerah Bogor khususnya di Kecamatan Rumpin dan sekitarnya berasal dari Daerah Cianjur, di mana para ajengan di sana melarang penggunaan media tersebut dan bahkan menuliskannya dalam beberapa kitab. Larangan penggunaan Spekaer dan lainnya oleh Guru Pesantren maupun Guru ngaji di daerah Kecamatan Rumpin ngaji mengukuti ajaran dari para gurunya, yang pernah ngaji ke Gentur Cianjur kemudian ajaran tersebut di lakukan di komunitasnya masing-masing. Kearifan lokal anti speaker ini sebenarnya tidak hanya berlaku di beberapa tempat di daerah Rumpin saja, namun juga berlaku di bebrapa kecamatan sekitarnya seperti Cigudeg dan lainya di Bogor.

\section{DAFTAR RUJUKAN}

Afia, Neng Darol. Tradisi dan kepercayaan lokal pada beberpa suku di Indonesia, Litbang Agama Departemen Agama RI. Jakarta.

Arikunto,Suharsimi.2010. Prosedur penelitian suatu pendekatan praktik. Jakarta: Rineka cipta

Ayatrohaedi. 1986. Kepribadian Budaya Bangsa (Local Genius). Jakarta: Pustaka Jaya.

Budiawanti , Erni. 2000. Islam Sasak Wetu Telu Versus Waktu Lima Yogyakarta. Lkis.

Geertz, Clliford, 1992, Tafsir Kebudayaan, terjemahan, Kanisius, Yogyakarta.

Hadikusuma, Hilman. 2005. Bahasa Hukum Indonesia. Bandung: PT. Alumni.

Hanafi, 1970. Pengantar dan Sejarah Hukum Islam. Jakarta: PT. Bulan Bintang.

Harjono, Anwar. 1987. Hukum Islam" Keluasan dan Keadilan. Jakarta: PT. Bulan Bintang

Husaini Usman dan Purnomo Setiadi Akbar. 2009. Metodologi Penelitian Sosial, Jakarta: PT Bumi Aksara,

Kahmad Dadang. 2000. Sosiologi Agama. Bandung. PT. Remaja Rosdakarya.

Kasmuri Selamat, dan Ihsan Sanusi. 2012. Akhlak Tasawuf" Upaya Meraih Kehalusan Budi dan Kedekatan Ilahi. Jakarta: Kalam Mulia.

Lexy J. Moleong, 2000. Metodologi Penelitian Kualitatif, Bandung: Remaja Rosdakarya. 
Littlejohn, Stephen W. Karen .S. Foss. 2004. Theories of Human Communicatoin eighth Edition. New York: Thomson.

Lutf, Sebastian. 2011. Subjectivity and Lifeword in Transcendental Phenomonology, Revew Books Northwestern University Press.

Mardiah, Ainun. 2015. Nilai Gotong Royong Dalam Istiadat Ritual Khitanan Pada Masyarakat Melayu Langkat Di Desa Secanggang. Skripsi. Medan: Universitas Sumatera Utara.

Marfai ,Muh Aris. 2012. Pengantar Etika Lingkungan dan Kearifan Lokal. Yogyakarta: Gajah Mada University press.

Meleong, Lexy J.2010. Metode Penelitian Kulitatif. Bandung: PT Remaja Rosdakarya.

Mudji Sutrisno dan Hendar Putranto 2005, TeoriTeori Kebudayaan, Penerbit Kanisius: Yogyakarta

Mundzirin Yusuf dkk. 2015. Islam dan Budaya Lokal. Yogyakarta: Pokja Akademik UIN Sunan Kalijaga.

Rahyono, F.X. 2009. Kearifan Budaya dalam kata. Jakarta: Penerbit Kompas

Sibarani, Robert. 2012. Kearifan Lokal Hakikat, Peran, Dan Metode Tradisi Lisan. Jakarta Selatan: Asosiasi Tradisi Lisan (ATL).
Sudarto, 1997. Metodologi Penelitian Filsafat, Jakarta: Raja Grafindo Persada.

Sudarwan Danim, 2002. Menjadi Peneliti Kualitatif Rancangan Metodologi, Presentasi, dan Publikasi, Bandung: Remaja Rosdakarya.

Sugiyono, 2012. Metode Penelitian Kualitatif, Kuantitatif, dan R\&D, Jakarta: Alfabeta.

Suhartini. 2009. Kajian Kearifan Lokal Masyarakat dalam Pengelolaan Sumberdaya Alam dan Lingkungan. http://staff.uny.ac.id diakses 6 Januari 2019.

Regita Puji Agustin, Adi Suparwo, Wulan Yuliyana, Denok Sunarsi, \& Nurjaya. (2021). Pengaruh Kualitas Pelayanan terhadap Kepuasan Pelanggan serta dampaknya pada Word of Mouth Jasa Pengurusan Nenkin di CV Speed Nenkin. JIIP - Jurnal Ilmiah Ilmu Pendidikan, 4(3), 186-190. Retrieved from http://jiip.stkipyapisdompu.ac.id/jiip/index .php/IIIP/article/view/249

Sugiyono, P. D. (2019). Metode Penelitian; Kualitatif, Kuantitatif dan Campuran. Bandung: Alfabeta.

Sutisna dan Sunyoto.Perilaku Konsumen \&Komunikasi Pemasaran. Bandung: Remaja Rosdakarya 